\title{
Effects of electrical stimulation on muscle power and biochemical markers during hemodialysis in elderly patients: a pilot randomized clinical trial
}

Misa Miura ${ }^{1 *} \mathbb{D}$, Aki Hirayama ${ }^{1}$, Shigeru Oowada ${ }^{2}$, Akihito Nishida ${ }^{1}$, Chie Saito ${ }^{3}$, Kunihiro Yamagata ${ }^{3}$, Osamu Ito ${ }^{4}$, Yo Hirayama ${ }^{5}$ and Masahiro Kohzuki ${ }^{6}$

\begin{abstract}
Background: Decreased physical activity in hemodialysis (HD) patients causes various structural, metabolic, and functional abnormalities due to uremic changes in skeletal muscles. Electrical stimulation (ES) of the lower limbs was found to be effective in patients with cardiac insufficiency for exercise tolerance. This study compared the effects of ES and variable load ergometers on the lower limbs in HD patients.

Methods: We performed a prospective, double-center, open-label, randomized controlled trial. Eligible patients were aged over 65 years, had end-stage renal disease, and underwent maintenance HD. The primary endpoint was muscle power, and the secondary endpoints included changes in dialysis efficiency, serum phosphorus, and inflammatory markers. Thirty HD outpatients were randomly assigned to the following groups: exercise (EX), ES, or control (SED). In EX and ES groups, patients were instructed to exercise twice a week for 12 weeks, depending on their physical capabilities. The safety and efficacy of aerobic training and ES during HD were confirmed when a sudden decrease in blood pressure or any other side effects did not occur. A repeated measures analysis of variance was performed as the principal method to evaluate time (baseline vs. 12 weeks) and group (EX vs. ES vs. SED) comparisons for the experimental outcomes.

Results: The efficiency of HD significantly increased in the ES and EX groups $(p \leq 0.02)$. Moreover, the ES group experienced a significant increase in muscle power $(p=0.01)$ and the weight bearing index $(p=0.04)$ and a significant decrease in serum phosphorus level $(p=0.04)$ and tumor necrosis factor-alpha (TNF-a) level $(p=0.04)$ from baseline to 12 weeks. Furthermore, there was a significant increase in serum TNF-a level $(p \leq 0.03)$ over time in both the EX and SED groups.

Conclusion: The safety and efficacy of aerobic training and ES during HD were confirmed when a sudden decrease in blood pressure or any other side effects did not occur. Therefore, ES may improve the patient's condition, similar to lower limb exercises, and ES should be considered as an option for rehabilitation programs in HD patients.
\end{abstract}

Trial registration: UMIN Clinical Trials Registry (UMIN-CTR R 000032202); retrospectively registered on April 11, 2018 Keywords: Elderly hemodialysis patients, Lower limb electrical stimulation, Aerobic exercise, Hemodialysis sessions

\footnotetext{
* Correspondence: m.miura@k.tsukuba-tech.ac.jp

${ }^{1}$ Faculty of Health Sciences, Tsukuba University of Technology, Kasuga 4-12-7,

Tsukuba City, Ibaraki 305-8521, Japan

Full list of author information is available at the end of the article
}

(C) The Author(s). 2018 Open Access This article is distributed under the terms of the Creative Commons Attribution 4.0 International License (http://creativecommons.org/licenses/by/4.0/), which permits unrestricted use, distribution, and reproduction in any medium, provided you give appropriate credit to the original author(s) and the source, provide a link to the Creative Commons license, and indicate if changes were made. The Creative Commons Public Domain Dedication waiver (http://creativecommons.org/publicdomain/zero/1.0/) applies to the data made available in this article, unless otherwise stated. 


\section{Background}

Chronic kidney disease (CKD) is a major contemporary health problem. The number of patients with CKD continues to increase globally, with a current estimate of 2.6 million CKD patients worldwide [1]. Patients with CKD are at a higher risk of various complications, such as high blood pressure and heart disease, in addition to the frequent occurrence of chronic inflammation, renal anemia, and sarcopenia [2]. While exercise is reported to improve chronic inflammation [3], recent reports have noted that electrical stimulation (ES) is effective not only in patients with moderate to severe heart failure [4], but also in hemodialysis (HD) patients [5]. ES and voluntary muscular contractions during cycle ergometer training are different ways of activating muscle fibers that influence a number of acute changes in the neuromuscular system [5]. ES activates type I muscle fibers, while anaerobic exercise activates type II muscle fibers. In addition, conventional training using cycle ergometers is a whole-body exercise, whereas ES is a static and localized body exercise. Therefore, ES might be effective for elderly patients undergoing HD who have disease complications.
Based on this perspective, achieving a higher training benefit in HD patients would be of great importance. However, effects of ES on physical function and indicators of biochemical changes in maintenance HD patients are unknown. Therefore, this study aimed to evaluate and compare the effects of ES on muscle strength, dialysis efficiency, and serum inflammatory markers, including cytokine factors in elderly patients undergoing maintenance HD.

\section{Methods}

\section{Study design and participants}

This study was a prospective, double-center, open-label, randomized controlled trial. Subjects included stable patients on maintenance HD who underwent outpatient HD treatments three times a week between February 2014 and March 2016 at two dialysis centers in Japan (Fig. 1). This study was approved by the Tohoku University Hospital Review Board (no. 2011-120-1) and the Tsukuba University of Technology Review Board (no. 05/02/2015). The study was also retrospectively registered on the UMIN Clinical Trials Registry (UMIN-CTR R 000032202).

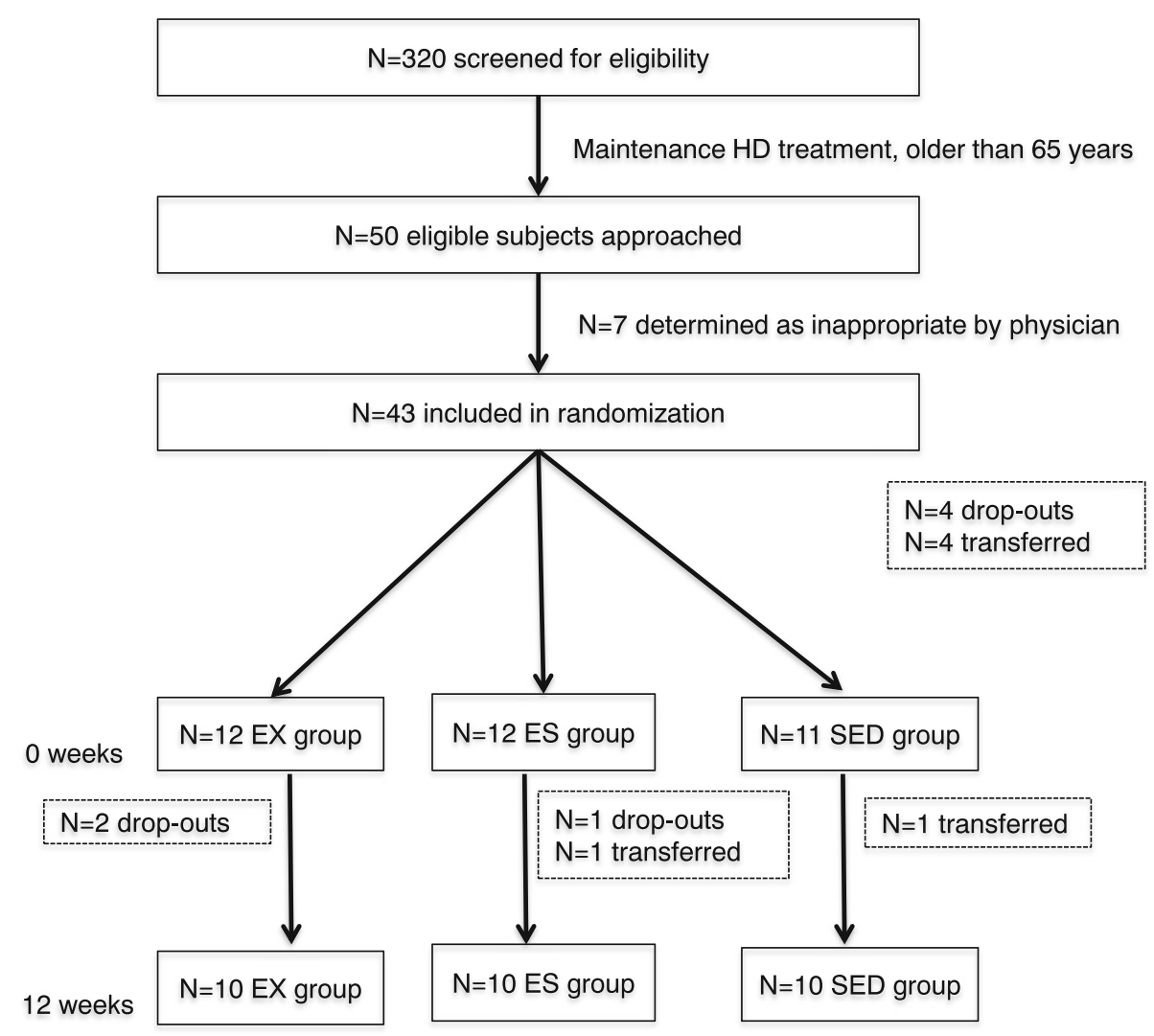

Fig. 1 Flow chart showing enrollment and grouping assignment of patients. Of 320 Japanese hemodialysis (HD) outpatients who were screened for eligibility, 50 consecutive patients who met the inclusion criteria were approached for study participation. Ultimately, 30 patients (23 men, 7 women) were included in this study. EX exercise, ES electrical stimulation, SED control 
At the initiation of the present study, we identified 320 patients who were undergoing maintenance $\mathrm{HD}$ at both dialysis centers. The inclusion criteria were as follows: (1) patients who underwent dialysis treatment for at least 3 months and (2) age older than 65 years. The exclusion criteria were (1) acute coronary syndrome, particularly unstable angina and acute myocardial infarction; (2) systolic blood pressure $\geq 180 \mathrm{mmHg}$ or diastolic blood pressure $\geq$ $110 \mathrm{mmHg}$; and (3) patients who were determined as inappropriate for the study by the attending physician. The first 50 eligible patients were consecutively approached to participate in this study; however, 7 patients were further excluded because a physician determined that they were inappropriate for this study. As a result, 43 patients were initially included. Of these 43 patients, 13 patients withdrew from participation due to poor physical conditions. Finally, 30 subjects ( 23 men and 7 women) were randomly assigned to one of three groups ( $n=10$ per group).

\section{Randomization}

Eligible patients were randomized to one of three groups described below. After the first evaluation, randomization was generated using online software (www.random.org). The three groups included a group that exercised on a variable load ergometer (EX group), a group that underwent low-frequency ES of the lower limbs (ES group), and a group that underwent standard HD treatment without exercise (SED). The median age of the subjects was $71.5 \pm$ 1.6 years, and their mean time on dialysis was $10.7 \pm$ 1.9 years. All subjects were minimally active and exercised less than once per week before the intervention. After patient selection, the sequence of numbers was generated by researchers who were blinded to the study. Prior to the start of the intervention program, the sequence of numbers was only disclosed to the expert nurse or the physical therapist who was responsible for applying the respective treatment (ES, EX, or SED) to ensure concealment of the allocation sequence and to keep patients blinded to the type of intervention.

Using the G*power statistics software (version 3.1; Heinrich-Heine-University, Düsseldorf, Germany), sample size calculation was performed based on a $5 \%$ alpha error and $80 \%$ power for a magnitude of effect of 1.181 . To calculate the sample size, a mean between group difference of $3.9 \pm 0.2 \mathrm{kgf}$ for muscle power of the quadriceps femoris (MPQ) was used, as reported by Banerjee et al. [6]. According to the calculation performed, a sample of 10 subjects was required in each group.

\section{Data collection}

Physical parameters included baseline demographic characteristics, hand grip strength, leg muscle force, and weight bearing index (WBI) conversion. Biochemical parameters included dialysis efficiency, serum blood urea nitrogen (BUN), phosphorus, high-density lipoprotein cholesterol (HDL-C), low-density lipoprotein cholesterol/ HDL-C (LDL-C/HDL-C), renal anemia indicators (ferritin [Fer] and transferrin saturation [TSAT]), nutritional status indicator (albumin), and inflammation markers (C-reactive protein [CRP], interleukin-6 [IL-6], and tumor necrosis factor-alpha [TNF- $\alpha])$. At baseline and 12 weeks after the intervention, these parameters were collected before the HD session and under the same conditions; all procedures were carried out using the same protocol at both dialysis centers.

\section{Hand grip strength}

At baseline and 12 weeks after the intervention, hand grip strength was measured before the HD session and under the same conditions by the expert nurse and physical therapists who were not informed about the study details. Hand grip strength was measured using the Smedley Hand Dynamometer (OG Giken, Okayama, Japan). Measurements were completed using the arm opposite to the arm in which vascular access was installed before the HD session. All measurements were performed with the patient in a seated position, the shoulder in adduction and in a neutral position, the elbow in $90^{\circ}$ flexion, and the forearm in a neutral position. The test was conducted three times with the subject exerting maximum force to ensure reliability, and the mean value of these three trials was recorded [7].

\section{Maximum isometric knee extensor muscle power of the quadriceps femoris (MPQ) and WBI conversion}

At baseline and 12 weeks after the intervention, physical conditions were measured before the HD session and under the same conditions. Maximum isometric knee extensor MPQ was measured using a handheld dynamometer (IsoforceGT-300; OG Wellness Technologies Co., Ltd., Okayama, Japan) by the expert nurse and physical therapists who were not informed about the study details. MPQ was measured from an initial seated position squarely with the hip and the knee joints at a $90^{\circ}$ angle. The test was measured twice on each leg, and the maximum value was used. The WBI was calculated as $\mathrm{WBI}=\mathrm{MPQ} /$ body weight $[8]$.

\section{Laboratory examination}

At baseline and 12 weeks after the intervention, blood samples were collected after at least $12 \mathrm{~h}$ of fasting, and before the HD session, from an antecubital vein via venipuncture. Dialysis efficiency (represented using Kt/ V) was calculated from body weight and BUN levels before and after dialysis using the Daugirdas formula [9] as follows. Single-pool Kt/V was calculated monthly using urea kinetic modeling equations derived from the following equation: (post: pre-dialysis plasma BUN ratio to estimate $\mathrm{k} . \mathrm{T} / \mathrm{v}$ and npcr: mathematical modeling) 
(second-generation logarithmic estimates of single-pool variable volume $\mathrm{kt} / \mathrm{v}$ : an analysis of error). $\mathrm{Kt} / \mathrm{V}=-\ln (R$ $-0.008 \times \mathrm{t})+[(4-3.5 \times R) \times \mathrm{UF} / W]$, where $R$ is the ratio of post-dialysis to pre-dialysis serum BUN concentration, $t$ is the duration of hemodialysis in hours, UF is the amount of ultrafiltration (in l) during the hemodialysis session, and $W$ is the post-dialysis weight (in $\mathrm{kg}$ ) [10]. Serum BUN, phosphorus, HDL-C, LDL-C/HDL-C, Fer, TSAT, albumin, CRP, IL- 6 , and TNF- $\alpha$ were analyzed at SRL Co., Ltd., Tokyo, Japan.

\section{Conventional aerobic training (exercise with variable load ergometers)}

Subjects exercised for $1 \mathrm{~h}$ or less during the first half of the HD session twice a week for 12 consecutive weeks using a cycle ergometer (TE2-70; Showa Denki Co., Ltd., Osaka, Japan). Exercise duration was determined based on an exercise intensity relative to levels $11-13$ on the Borg Rating of Perceived Exertion (RPE) scale. RPE was recorded, and time limits were set depending on the subject's physical conditions. The exercise was performed at an intensity where the subject's heart rate did not exceed $30 \mathrm{bpm}$ above resting heart rate.

\section{Low-frequency ES}

A low-frequency ES device (Espurge, Ito Co., Ltd., Tokyo, Japan) was used. Electrodes were attached to the bilateral quadriceps femoris and triceps surae muscles. ES was applied at $10 \mathrm{~Hz}$ below the subject's pain threshold and was turned on and off in 20-s cycles. Subjects underwent ES for $1 \mathrm{~h}$ or less during the first half of the HD session twice a week for 12 consecutive weeks $[4,5]$. ES was applied such that the subject's heart rate did not exceed $30 \mathrm{bpm}$ above resting heart rate.

\section{Statistical analysis}

Estimates of arithmetic mean and standard error were used as standard summary statistics while obtaining primary data. Prior to parametric data processing, we verified sample distribution normality (Shapiro-Wilk's test) and variance homogeneity. Two-way repeated measures analysis of variance was performed as the principal method to evaluate the outcomes of the experimental groups (ES, EX, and SED as independent, effect components) and sampling at different time points (as a dependent, pairwise component). A post hoc test was completed for variables with a significant difference depending on their parameters (Tukey-Kramer or Scheffé procedures). Greenhouse-Geisser correction was applied as Mauchly's test of sphericity was not met. SPSS 22.0 for Windows (IBM Corp., Armonk, NY, USA) was used for all analyses, and a value of $p<0.05$ was considered statistically significant.

\section{Results}

Table 1 displays the subjects' baseline characteristics. There were no significant differences among the three groups at baseline in terms of age, male/female ratio, HD duration, body mass index, and diabetic nephropathy ratio (Table 1).

Physical parameters at baseline and 12 weeks after the intervention are presented in Table 2. With the exception of hand grip strength, there were no significant differences among the groups at baseline. After the 12-week intervention, the EX group showed a significant improvement in hand grip strength (from $19.7 \pm 0.7$ to $21.9 \pm 0.8 \mathrm{~kg} ; p=0.02$ ). In contrast, MPQ (from $13.1 \pm$ 0.1 to $15.7 \pm 1.6 \mathrm{kgf} ; p=0.01$ ) and WBI (from $0.2 \pm 0.1$ to $0.3 \pm 0.1 \mathrm{kgf} / \mathrm{kg} ; p=0.04)$ significantly increased in the ES group only.

Biochemical parameters at baseline and 12 weeks after the intervention are presented in Table 3. Dialysis efficiency (evaluated via $\mathrm{Kt} / \mathrm{V}$ ) significantly improved in both the ES (from $1.3 \pm 0.0$ to $1.5 \pm 0.0 ; p=0.01$ ) and EX groups (from $1.3 \pm 0.0$ to $1.5 \pm 0.0 ; p=0.02$ ), but not in the SED group. Phosphorus level significantly decreased (from $6.0 \pm 0.0$ to $4.7 \pm 0.1 \mathrm{mg} / \mathrm{dl} ; p=0.04$ ) in the ES group. HDL-C level significantly decreased in the both the EX and ES groups; however, LDL-C/HDL-C level did not significantly change in these groups. Regarding immunological factors, in the EX group, serum CRP level significantly decreased (from $0.7 \pm 0.1$ to $0.4 \pm$ $0.1 \mathrm{mg} / \mathrm{dl} ; p=0.04$ ), while serum TNF- $\alpha$ level significantly increased (from $6.5 \pm 1.0$ to $7.0 \pm 0.3 \mathrm{pg} / \mathrm{ml} ; p=$ 0.03 ). Similarly, serum TNF- $\alpha$ level increased (from 6.2 \pm 0.5 to $9.3 \pm 0.8 \mathrm{pg} / \mathrm{ml} ; p=0.02$ ) in the SED group, with no change detected in serum CRP after the 12-week intervention. Conversely, although serum CRP did not change, serum TNF- $\alpha$ level significantly decreased (from $6.7 \pm 0.3$ to $4.5 \pm 0.1 \mathrm{pg} / \mathrm{ml} ; p=0.04)$ in the ES group.

Table 1 Patient baseline characteristics separated by experimental groups

\begin{tabular}{lllll}
\hline Parameter & ES $(n=10)$ & EX $(n=10)$ & SED $(n=10)$ & $p$ value $^{*}$ \\
\hline Age (years) & $68.6 \pm 1.4$ & $72.1 \pm 0.7$ & $69.9 \pm 0.9$ & 0.78 \\
Male/female & $7 / 3$ & $8 / 2$ & $8 / 2$ & 0.85 \\
Duration of & $126.0 \pm 8.4$ & $111.6 \pm 4.8$ & $123.6 \pm 3.6$ & 0.10 \\
HD (months) & & & & 0.99 \\
BMI (kg/m $\left.{ }^{2}\right)$ & $22.0 \pm 0.9$ & $22.0 \pm 0.6$ & $22.0 \pm 0.7$ & 0.89 \\
Diabetic nephropathy & $60.0 \%$ & $70 \%$ & $60 \%$ & 0.96
\end{tabular}

Categorical data are presented as absolute number and percentage and continuous variables are presented as mean \pm standard error

ES electrical stimulation of the leg extensors was applied to the patients during hemodialysis, $E X$ the exercise-training group performed ergometertraining exercise during hemodialysis, SED the control group consisted of patients without exercise, $H D$ hemodialysis, $B M I$ body mass index ${ }^{*}$ Group comparisons were analyzed via the Kruskal-Wallis test and one-way analysis of variance for continuous parameters 
Table 2 Changes in physical parameters in the ES $(n=10)$, EX $(n=10)$, and SED $(n=10)$ groups

\begin{tabular}{|c|c|c|c|c|}
\hline \multirow[t]{2}{*}{ Parameter } & \multicolumn{2}{|l|}{ Mean $\pm S E$} & \multirow[t]{2}{*}{ 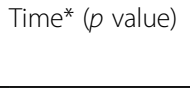 } & \multirow{2}{*}{$\begin{array}{l}\text { Repeated measures } \\
\text { ANOVA }^{+}(p \text { value) }\end{array}$} \\
\hline & Baseline & 12 weeks & & \\
\hline \multicolumn{5}{|c|}{ Hand grip (kg) } \\
\hline ES & $17.0 \pm 0.7$ & $18.8 \pm 0.8$ & 0.14 & Group 0.01 \\
\hline EX & $19.7 \pm 0.7$ & $21.9 \pm 0.8$ & 0.02 & Time 0.04 \\
\hline SED & $27.9 \pm 0.7$ & $26.1 \pm 0.8$ & 0.22 & Interaction 0.41 \\
\hline $\begin{array}{l}\text { Group }^{\ddagger} \\
\text { ( } p \text { value) }\end{array}$ & 0.01 & 0.44 & & \\
\hline \multicolumn{5}{|l|}{ MPQ (kgf) } \\
\hline ES & $13.1 \pm 0.1$ & $15.7 \pm 1.6$ & 0.01 & Group 0.53 \\
\hline EX & $9.2 \pm 0.3$ & $10.0 \pm 0.4$ & 0.24 & Time 0.04 \\
\hline SED & $9.3 \pm 0.2$ & $9.1 \pm 0.2$ & 0.43 & Interaction 0.78 \\
\hline $\begin{array}{l}\text { Group }^{\ddagger} \\
(p \text { value })\end{array}$ & 0.30 & 0.01 & & \\
\hline \multicolumn{5}{|c|}{ WBI (kgf/kg) } \\
\hline ES & $0.2 \pm 0.1$ & $0.3 \pm 0.1$ & 0.04 & Group 0.69 \\
\hline EX & $0.2 \pm 0.0$ & $0.2 \pm 0.1$ & 0.11 & Time 0.02 \\
\hline SED & $0.2 \pm 0.0$ & $0.2 \pm 0.0$ & 0.33 & Interaction 0.73 \\
\hline $\begin{array}{l}\text { Group }^{\ddagger}(p \\
\text { value) }\end{array}$ & 0.32 & 0.51 & & \\
\hline
\end{tabular}

ES electrical stimulation, EX exercise, SED control, SE standard error, ANOVA analysis of variance, $M P Q$ muscular power of the quadriceps, $W B I$ weight bearing index

*Time-related differences within each group analyzed via post hoc test was completed for variables with a significant difference depending on their parameters (Tukey-Kramer or Scheffé procedures). Greenhouse-Geisser correction was applied as Mauchly's test of sphericity was not met pairwise †Main effects (time and group) and interaction effect (time by group) analyzed via two-way repeated measures ANOVA

‡Group comparisons within each time point analyzed via post hoc test

There were no significant changes in other parameters and in group differences.

\section{Discussion}

To our knowledge, the present study was the first to investigate the effect of ES of skeletal muscles and aerobic training on physical function and biochemical parameters in elderly patients with CKD. Our major finding was that MPQ, WBI, Kt/V, serum phosphorus, and TNF- $\alpha$ level significantly changed from baseline to 12 weeks after the intervention in the ES group; however, there were no significant differences among the three groups at baseline for any parameters, except for hand grip strength. Additionally, in the EX and ES groups, HDL-C level significantly decreased from baseline to 12 weeks after the intervention, but no change was observed for LDL-C/HDL-C level. Therefore, these results support our hypothesis that training twice per week for 12 weeks during HD sessions in elderly patients with ESRD improves physical function and biochemical markers without any adverse effects.
However, the indicators of muscle power for the lower limbs (MPQ and WBI) significantly changed in the ES group only. The major difference between exercising on a cycle ergometer and lower leg ES is that the former is an endurance exercise of the lower limbs [11], whereas the latter induces muscle contraction without local articular exercise [4]. Both cycle exercise and lower limb ES involve muscle contraction. During cycle exercises, the appropriate number of motor units is recruited according to the exercise intensity, whereas ES may activate all motor units simultaneously [12]. That is, the major difference may be the possibility of ES to recruit the same number of motor units as high intensity exercises even at a low intensity. In the present study, the EX and ES groups conducted aerobic exercises at the same intensity (RPE 11-13). A preliminary experiment of expired gas measurement in two healthy individuals who underwent cycle ergometer exercise and lower leg ES revealed that the exercise was at or below an anaerobic threshold level for both tests. Therefore, the following reasons explain the lack of changes in muscle power in the EX group. Meanwhile, hand grip strength significantly improved in both the ES and EX groups. Several studies reported that improvement of muscle power in the lower limbs correlated with that in the upper limbs [13-15], which was similar with the results of the current study.

First, the exercise completed in this study was an endurance training of whole-body exercise [16], which may have improved endurance but was likely not enough to improve power in the EX group. The present study showed that in the ES group, MPQ increased while HDL-C significantly decreased with no changes in the other parameters. Although there is evidence that physical activity is beneficial in the general population, more work is required to determine the overall effects of exercise on physical activity in elderly patients with ESRD. Second, the exercise was performed at an RPE of 11-13 in the EX group, which may not have been high enough to reinforce muscle strength [17]. However, changes were observed in the ES and SED groups, as well as significant changes in inflammation markers CRP and TNF- $\alpha$ after the 12-week intervention. In addition, Kt/V significantly increased after the intervention in the ES and EX groups, whereas serum phosphorus and serum TNF- $\alpha$ levels significantly decreased in the ES group only. According to previous studies $[4,5,18]$, ES of the legs was equally effective as exercise, but its effects were dependent on localized increases in muscular strength [19]. The present results also demonstrate that WBI increased because the leg muscles were strengthened. The reason for this finding is that ES only affects local function. Several investigators have examined the effects of repeated ES on muscle strength and reported increased 
Table 3 Changes in biochemical parameters in the ES $(n=10)$, EX $(n=10)$, and SED $(n=10)$ groups

\begin{tabular}{llll}
\hline Parameter & Mean \pm SE & $\begin{array}{l}\text { Time }^{*} \\
\text { ( } p \text { value) }\end{array}$ & $\begin{array}{l}\text { Repeated measures } \\
\text { ANOVA }^{\dagger}(p \text { value) }\end{array}$ \\
\cline { 2 - 3 } & Baseline 12 weeks & \\
\hline
\end{tabular}

\begin{tabular}{cllll}
\hline Kt $N$ & & & & \\
ES & $1.3 \pm 0.0$ & $1.5 \pm 0.0$ & 0.01 & Group 0.04 \\
EX & $1.3 \pm 0.0$ & $1.5 \pm 0.0$ & 0.02 & Time 0.01 \\
SED & $1.3 \pm 0.0$ & $1.3 \pm 0.0$ & 0.47 & Interaction 0.65 \\
Group $^{\ddagger}$ & 0.23 & 0.04 & &
\end{tabular}

( $p$ value)

BUN (mg/dl)

$\begin{array}{clll}\text { ES } & 6.7 \pm 0.3 & 5.5 \pm 0.1 & 0.35 \\ \text { EX } & 5.5 \pm 0.1 & 5.0 \pm 0.3 & 0.58 \\ \text { SED } & 6.2 \pm 0.5 & 6.3 \pm 0.8 & 0.33 \\ \text { Group }^{\ddagger} & 0.977 & 0.908\end{array}$

Phosphorus (mg/dl)

$\begin{array}{cllll}\text { ES } & 6.0 \pm 0.0 & 4.7 \pm 0.1 & 0.04 & \text { Group } 0.04 \\ \text { EX } & 5.3 \pm 0.1 & 5.1 \pm 0.1 & 0.52 & \text { Time } 0.04 \\ \text { SED } & 4.7 \pm 0.1 & 5.4 \pm 0.1 & 0.50 & \text { Interaction } 0.43 \\ \begin{array}{c}\text { Group } \\ (p \text { value })\end{array} & 0.39 & 0.59 & & \\ \begin{array}{c}\text { Potassium (mEq/l) } \\ \text { ES }\end{array} & 5.3 \pm 0.1 & 5.0 \pm 0.0 & 0.08 & \text { Group } 0.93 \\ \text { EX } & 4.8 \pm 0.1 & 4.6 \pm 0.2 & 0.88 & \text { Time } 0.74 \\ \text { SED } & 4.7 \pm 0.1 & 4.8 \pm 0.1 & 0.96 & \text { Interaction } 0.63 \\ \begin{array}{c}\text { Group } \\ \text { value })\end{array} & 0.55 & 0.59 & & \\ \text { Alb }(\mathrm{g} / \mathrm{dl}) & & & & \end{array}$

Alb $(\mathrm{g} / \mathrm{dl})$

$\begin{array}{cllll}\text { ES } & 3.6 \pm 0.0 & 3.5 \pm 0.0 & 0.58 & \text { Group } 0.72 \\ \text { EX } & 3.4 \pm 0.1 & 3.5 \pm 0.0 & 0.55 & \text { Time } 0.95 \\ \text { SED } & 3.6 \pm 0.0 & 3.6 \pm 0.0 & 0.80 & \text { Interaction } 0.07 \\ \begin{array}{c}\text { Group } \\ \text { value })\end{array} & 0.69 & 0.91 & & \end{array}$

$\mathrm{Hb}(\mathrm{g} / \mathrm{dl})$

\begin{tabular}{|c|c|c|c|c|}
\hline ES & $10.4 \pm 0.1$ & $10.3 \pm 0.1$ & 0.91 & Group 0.21 \\
\hline EX & $10.8 \pm 0.1$ & $10.3 \pm 0.1$ & 0.41 & Time 0.49 \\
\hline SED & $11.0 \pm 0.1$ & $11.0 \pm 0.1$ & 0.91 & Interaction 0.77 \\
\hline $\begin{array}{l}\text { Group }^{\ddagger} \\
\text { ( } p \text { value) }\end{array}$ & 0.766 & 0.309 & & \\
\hline \multicolumn{5}{|c|}{ Fer (ng/ml) } \\
\hline ES & $\begin{array}{l}118.9 \pm \\
11.9\end{array}$ & $\begin{array}{l}181.4 \pm \\
15.9\end{array}$ & 0.24 & Group 0.10 \\
\hline EX & $\begin{array}{l}133.7 \pm \\
11.9\end{array}$ & $\begin{array}{l}179.3 \pm \\
17.4\end{array}$ & 0.11 & Time 0.07 \\
\hline SED & $84.5 \pm 3.8$ & $91.1 \pm 6.1$ & 0.79 & Interaction 0.43 \\
\hline $\begin{array}{l}\text { Group }^{\ddagger} \\
\text { ( } p \text { value) }\end{array}$ & 0.43 & 0.20 & & \\
\hline
\end{tabular}

TSAT (\%)
Table 3 Changes in biochemical parameters in the ES $(n=10)$, EX $(n=10)$, and SED $(n=10)$ groups (Continued)

\begin{tabular}{|c|c|c|c|c|}
\hline \multirow[t]{2}{*}{ Parameter } & \multicolumn{2}{|l|}{ Mean \pm SE } & \multirow{2}{*}{$\begin{array}{l}\text { Time* } \\
\text { ( } p \text { value) }\end{array}$} & \multirow{2}{*}{$\begin{array}{l}\text { Repeated measures } \\
\text { ANOVA }^{\dagger}(p \text { value) }\end{array}$} \\
\hline & Baseline & 12 weeks & & \\
\hline EX & $21.9 \pm 0.5$ & $24.8 \pm 0.6$ & 0.50 & Time 0.07 \\
\hline SED & $23.5 \pm 0.9$ & $26.5 \pm 1.0$ & 0.53 & Interaction 0.43 \\
\hline $\begin{array}{l}\text { Group }^{\ddagger} \\
(p \text { value })\end{array}$ & 0.90 & 0.89 & & \\
\hline \multicolumn{5}{|c|}{$\mathrm{HDL}-\mathrm{C}(\mathrm{mg} / \mathrm{dl})$} \\
\hline ES & $50.6 \pm 1.1$ & $47.9 \pm 0.7$ & 0.03 & Group 0.16 \\
\hline EX & $43.2 \pm 0.8$ & $45.1 \pm 1.2$ & 0.03 & Time 0.04 \\
\hline SED & $43.2 \pm 1.3$ & $43.4 \pm 1.1$ & 0.13 & Interaction 0.69 \\
\hline $\begin{array}{l}\text { Group }^{\ddagger} \\
(p \text { value })\end{array}$ & 0.27 & 0.47 & & \\
\hline \multicolumn{5}{|c|}{ LDL-C/HDL-C } \\
\hline ES & $1.8 \pm 0.1$ & $1.9 \pm 0.1$ & 0.39 & Group 0.52 \\
\hline EX & $2.0 \pm 0.1$ & $2.0 \pm 0.1$ & 0.58 & Time 0.22 \\
\hline SED & $2.1 \pm 0.0$ & $2.2 \pm 0.1$ & 0.37 & Interaction 0.87 \\
\hline $\begin{array}{l}\text { Group }^{\ddagger} \\
\text { ( } p \text { value })\end{array}$ & 0.51 & 0.79 & & \\
\hline \multicolumn{5}{|c|}{ CRP (mg/dl) } \\
\hline ES & $0.4 \pm 0.1$ & $0.3 \pm 0.1$ & 0.47 & Group 0.41 \\
\hline EX & $0.7 \pm 0.1$ & $0.4 \pm 0.1$ & 0.04 & Time 0.04 \\
\hline SED & $0.2 \pm 0.0$ & $0.2 \pm 0.0$ & 0.70 & Interaction 0.75 \\
\hline $\begin{array}{l}\text { Group }^{\ddagger} \\
\text { ( } p \text { value })\end{array}$ & 0.46 & 0.80 & & \\
\hline \multicolumn{5}{|c|}{ IL-6 (pg/mL) } \\
\hline ES & $6.7 \pm 0.2$ & $6.9 \pm 0.5$ & 0.89 & Group 0.61 \\
\hline EX & $4.4 \pm 0.2$ & $4.6 \pm 0.2$ & 0.48 & Time 0.25 \\
\hline SED & $5.4 \pm 0.3$ & $6.5 \pm 0.4$ & 0.14 & Interaction 0.93 \\
\hline $\begin{array}{l}\text { Group }^{\ddagger} \\
(p \text { value })\end{array}$ & 0.38 & 0.55 & & \\
\hline \multicolumn{5}{|c|}{ TNF-a (pg/ml) } \\
\hline ES & $6.7 \pm 0.3$ & $4.5 \pm 0.1$ & 0.04 & Group 0.23 \\
\hline EX & $6.5 \pm 1.0$ & $7.0 \pm 0.3$ & 0.04 & Time 0.04 \\
\hline SED & $6.2 \pm 0.5$ & $9.3 \pm 0.8$ & 0.03 & Interaction 0.32 \\
\hline $\begin{array}{l}\text { Group }^{\ddagger} \\
\text { ( } p \text { value) }\end{array}$ & 0.40 & 0.03 & & \\
\hline
\end{tabular}

ES electrical stimulation, EX exercise, SED control, SE standard error, ANOVA analysis of variance, $M P Q$ muscular power of the quadriceps, $W B I$ weight bearing index, ES electrical stimulation, EX exercise, SED control, SE standard error, ANOVA analysis of variance, $K t / N$ hemodialysis efficiency, $B U N$ blood urea nitrogen, Alb albumin, $\mathrm{H} b$ hemoglobin, Fer ferritin, TSAT transferrin saturation, $H D L-C$ high-density lipoprotein cholesterol, LDL-C low-density lipoprotein cholesterol, CRP C-reactive protein, IL6 interleukin-6, TNF-a tumor necrosis factor-alpha

*Time-related differences within each group analyzed via post hoc test was completed for variables with a significant difference depending on their parameters (Tukey-Kramer or Scheffé procedures). Greenhouse-Geisser correction was applied as Mauchly's test of sphericity was not met pairwise tMain effects (time and group) and interaction effect (time by group) analyzed via two-way repeated measures ANOVA

‡Group comparisons within each time point analyzed via post hoc test 
strength of the skeletal muscles, improved muscle contraction in patients after knee surgery, and decreased atrophy. These findings indicate that ES might prevent and ameliorate disuse atrophy due to immobilization without requiring excessive effort.

However, there were no changes in anemia- and cholesterol-related factors from baseline to the end of the intervention. The exercise intensity and limited intervention duration (12 weeks) may not have been sufficient to induce changes in these factors. Problems specific to ES include the potential for local skin burns or irritation, electrode sensitivity, autonomic dysreflexia, surface burns, and skin inflammation. Previous studies reported that exercise training could be performed during HD sessions without any adverse effects. Likewise, our subjects did not experience any adverse effects, such as a sudden drop in blood pressure or cardiovascular disease.

On the other hand, previous studies reported that exercise improves inflammation; however, in the current study, serum CRP level significantly decreased after the intervention in the EX group and serum TNF- $\alpha$ level significantly increased. This elucidates that CRP is an indicator of systemic inflammation, whereas TNF- $\alpha$ can fluctuate with exercise and cause changes in psychological or physiological conditions, in addition to inflammation [20]. Therefore, it is reasonable that the CRP and TNF- $\alpha$ levels diverged in the present study.

In addition, serum phosphorus level decreased in the ES group only. We believe that this was an effect of muscle contraction on phosphorus metabolism, as explained in previous research [21]. The onset of poor physical condition was associated with bone metabolism, and the emergence of sarcopenia was accompanied by increased levels of inflammatory factors TNF- $\alpha$ and IL-6 [22].

Furthermore, subjects in both the EX and ES groups were able to safely undergo the intervention without shunt trouble, sudden drop in blood pressure, or the need for fluid replacement. Previous studies also reported that intra-dialytic exercise prolongs vital prognosis without adverse events [23]. Likewise, ES has also been safely conducted in previous studies without causing skin problems or new-onset heart failure [4, 24]. Therefore, ES of the lower limbs has beneficial effects on muscle power, systemic inflammation, and the prevention of falls in elderly patients undergoing HD.

Some limitations of our study should be considered. First, the study involved a relatively small sample size, and the study period was too short to determine long-term effects of exercise. Future examinations on efficacy should include a larger sample size and include a selection of resistance training adapted for Asian patients of advanced age.

\section{Conclusion}

ES of the legs and cycle exercise can be safely performed during dialysis. A comparison of ES and EX suggested that ES was more effective in improving muscle power of the lower limbs and TNF- $\alpha$; therefore, ES might be effective for elderly patients with disease complications requiring HD.

\begin{abstract}
Abbreviations
BUN: Blood urea nitrogen; CKD: Chronic kidney disease; CRP: C-reactive protein; ES: Electrical stimulation; ESRD: End-stage renal disease; EX: Exercise; Fer: Ferritin; HD: Hemodialysis; HDL-C: High-density lipoprotein cholesterol; IL-6: Interleukin-6; LDL-C: Low-density lipoprotein cholesterol; MPQ: Muscle power of the quadriceps femoris; RPE: Rating of perceived exertion; SED: Control; TNF-a: Tumor necrosis factor-alpha; TSAT: Transferrin saturation; WBI: Weight bearing index
\end{abstract}

\section{Acknowledgements}

The authors would like to thank PT. Sugiura and Nrs. Nose for the technical assistance with the evaluation

\section{Funding}

This work was supported by the 2016 Renal Failure Pathological Research Grant of the Kidney Foundation in Japan.

\section{Availability of data and materials \\ The datasets analyzed in the present study are available from the} corresponding author upon reasonable request.

\section{Authors' contributions}

MM contributed to the study design, study procedure implementation, data collection, and manuscript writing. All other authors contributed to the study design, data analysis, and manuscript writing. All authors read and approved the final manuscript.

\section{Ethics approval and consent to participate}

All procedures involving human participants were in accordance with the ethical standards of the institution at which the studies were conducted with approval from the Tohoku University Hospital Review Board (IRB no. 2011-120-1) on June 10, 2011, and the Tsukuba University of Technology Review Board (IRB no. 05/02/2015) on February 5, 2015. This protocol was also retrospectively registered with the UMIN Clinical Trials Registry (UMIN-CTR R 000032202) on April 11, 2018. The study was conducted in compliance with the standards of the 1964 Helsinki declaration and its later amendments or comparable ethical standards. Informed consent was obtained from the patients to participate in this study.

\section{Consent for publication}

Not applicable.

\section{Competing interests}

The authors declare that they have no competing interests.

\section{Publisher's Note}

Springer Nature remains neutral with regard to jurisdictional claims in published maps and institutional affiliations.

\footnotetext{
Author details

${ }^{1}$ Faculty of Health Sciences, Tsukuba University of Technology, Kasuga 4-12-7, Tsukuba City, Ibaraki 305-8521, Japan. ${ }^{2}$ Asao Clinic, 1-8-10 Manpukuji, Asaoku, Kawasaki City, Kanagawa 215-0004, Japan. ${ }^{3}$ Department of Nephrology, Faculty of Medicine, University of Tsukuba, 2-1-1 Amakubo, Tsukuba City, Ibaraki 305-8576, Japan. ${ }^{4}$ Department of Internal Medicine and Rehabilitation, Faculty of Medicine, Tohoku Medical and Pharmaceutical University, Komatushima 4-4-1, Aobaku, Sendai City, Miyagi 981-0905, Japan. ${ }^{5}$ Hirayama Hospital, Hanamigawa1494-3, Hanamigawaku, Chiba City, Chiba 262-0046, Japan. ${ }^{6}$ Department of Internal Medicine and Rehabilitation Science, Tohoku University School of Medicine, 1-1 Seiryoumachi, Aobaku, Sendai City, Miyagi 980-8574, Japan.
} 
Received: 26 February 2018 Accepted: 24 July 2018

Published online: 05 September 2018

\section{References}

1. Bello AK, Levin A, Tonelli M, Okpechi IG, Feehally J, Harris D, et al. Assessment of global kidney health care status. JAMA. 2017;317(18):1864-81.

2. Collister D, Ferguson T, Komenda P, Tangri N. The patterns, risk factors, and prediction of progression in chronic kidney disease: a narrative review. Semin Nephrol. 2016;36(4):273-82.

3. Johansen KL. Exercise in the end-stage renal disease population. J Am Soc Nephrol. 2007:18(6):1845-54

4. Dobsák P, Nováková M, Fiser B, Siegelová J, Balcárková P, Spinarová L, et al Electrical stimulation of skeletal muscles. An alternative to aerobic exercise training in patients with chronic heart failure? Int Heart J. 2006;47(3):441-53.

5. Dobsak P, Homolka P, Svojanovsky J, Reichertova A, Soucek M, Novakova M, et al. Intra-dialytic electrostimulation of leg extensors may improve exercise tolerance and quality of life in hemodialyzed patients. Artif Organs. 2012; 36(1):71-8. https://doi.org/10.1111/j.1525-1594.2011.01302.x

6. Banerjee P, Caulfield B, Crowe L, Clark AL. Prolonged electrical muscle stimulation exercise improves strength, peak VO2, and exercise capacity in patients with stable chronic heart failure. J Card Fail. 2009;15(4):319-26.

7. Wardlaw JM, Chappell FM, Stevenson M, De Nigris E, Thomas S, Gillard J, et al. Accurate, practical and cost-effective assessment of carotid stenosis in the UK. Health Technol Assess. 2006:10(30):1-182. iii-iv, ix-x

8. Muraki S, Akune T, Teraguchi M, Kagotani R, Asai Y, Yoshida M, et al. Quadriceps muscle strength, radiographic knee osteoarthritis and knee pain: the ROAD study. BMC Musculoskelet Disord. 2015;16:305.

9. Goldstein SL, Sorof JM, Brewer ED. Evaluation and prediction of urea rebound and equilibrated $\mathrm{Kt} / \mathrm{N}$ in the pediatric hemodialysis population. Am J Kidney Dis. 1999:34(1):49-54.

10. Lertdumrongluk P, Streja E, Rhee CM, Park J, Arah OA, Brunelli SM, et al. Dose of hemodialysis and survival: a marginal structural model analysis. Am J Nephrol. 2014:39(5):383-91.

11. Elkington TJ, Cassar S, Nelson AR, Levinger I. Psychological responses to acute aerobic, resistance, or combined exercise in healthy and overweight individuals: a systematic review. Clin Med Insights Cardiol. 2017;11: 1179546817701725

12. Doucet BM, Lam A, Griffin L. Neuromuscular electrical stimulation for skeletal muscle function. Yale J Biol Med. 2012;85(2):201-15.

13. Melo FCM, de Lima KKF, Silveira A, de Azevedo KPM, Dos Santos IK, de Medeiros $\mathrm{HJ}$, et al. Physical training and upper limb strength of people with paraplegia: a systematic review. J Sport Rehabil. 2018;24:1-20. https://doi. org/10.1123/jsr.2017-0062

14. Baker J, Brown E, Hill G, Phillips G, Williams R, Davies B. Handgrip contribution to lactate production and leg power during high-intensity exercise. Med Sci Sports Exerc. 2002;34(6):1037-40.

15. Harvey S, Rissel C, Pijnappels M. Associations between bicycling and fall related physical performance in older adults. J Aging Phys Act. 2018;26(3): 514-19. https://doi.org/10.1123/japa.2017-0243

16. Hansen JS, Zhao X, Irmler M, Liu X, Hoene M, Scheler M, et al. Type 2 diabetes alters metabolic and transcriptional signatures of glucose and amino acid metabolism during exercise and recovery. Diabetologia. 2015; 58(8):1845-54

17. Borde R, Hortobagyi T, Granacher U. Dose-response relationships of resistance training in healthy old adults: a systematic review and metaanalysis. Sports Med. 2015:45(12):1693-720.

18. Bruggemann AK, Mello CL, Dal Pont T, Hizume Kunzler D, Martins DF, Bobinski $F$, et al. Effects of neuromuscular electrical stimulation during hemodialysis on peripheral muscle strength and exercise capacity: a randomized clinical trial. Arch Phys Med Rehabil. 2017:98(5):822-31. e821

19. Dobsak P, Homolka P, Svojanovsky J, Reichertova A, Soucek M, Novakova M, et al. Intra-dialytic electrostimulation of leg extensors may improve exercise tolerance and quality of life in hemodialyzed patients. Artif Organs. 2012; 36(1):71-8.

20. Ramseyer VD, Garvin JL. Tumor necrosis factor-alpha: regulation of renal function and blood pressure. Am J Physiol Renal Physiol. 2013;304(10):F1231-42.

21. Friedman MA, Bailey AM, Rondon MJ, McNerny EM, Sahar ND, Kohn DH. Calcium- and phosphorus-supplemented diet increases bone mass after short-term exercise and increases bone mass and structural strength after long-term exercise in adult mice. PLoS One. 2016;11(3):e0151995.
22. Bian AL, Hu HY, Rong YD, Wang J, Wang JX, Zhou XZ. A study on relationship between elderly sarcopenia and inflammatory factors IL-6 and TNF-alpha. Eur J Med Res. 2017;22(1):25.

23. Chung YC, Yeh ML, Liu YM. Effects of intradialytic exercise on the physical function, depression and quality of life for haemodialysis patients: a systematic review and meta-analysis of randomised controlled trials. J Clin Nurs. 2017;26(13-14):1801-13.

24. Graham-Brown MP, March DS, Churchward DR, Young HM, Dungey M, Lloyd S, et al. Design and methods of CYCLE-HD: improving cardiovascular health in patients with end stage renal disease using a structured programme of exercise: a randomised control trial. BMC Nephrol. 2016:17(1):69.
Ready to submit your research? Choose BMC and benefit from:

- fast, convenient online submission

- thorough peer review by experienced researchers in your field

- rapid publication on acceptance

- support for research data, including large and complex data types

- gold Open Access which fosters wider collaboration and increased citations

- maximum visibility for your research: over $100 \mathrm{M}$ website views per year

At $\mathrm{BMC}$, research is always in progress.

Learn more biomedcentral.com/submissions 